\title{
ANALYSIS AND REMEDIATION OF THE 2013 LAC-MÉGANTIC TRAIN DERAILMENT
}

\author{
Suzanne Brunke ${ }^{a}$, Guy Aubé ${ }^{\mathrm{b}}$, Serge Legaré ${ }^{\mathrm{c}}$, Claude Auger ${ }^{\mathrm{d}}$ \\ ${ }^{a}$ MDA, 13800 Commerce Parkway, Richmond, BC, Canada V6V 2J3 - sbrunke@mdacorporation.com \\ ${ }^{\text {b }}$ Canadian Space Agency, 6767 route de l'Aéroport, Saint-Hubert, Québec, Canada J3Y 8Y9 - guy.aube@ @anada.ca \\ ${ }^{c}$ Quebec Ministry of Public Security, 2525 Boulevard Laurier, 6e étage B, Quebec G1V 2L2 - serge.legare@ msp.gouv.qc.ca \\ ${ }^{\mathrm{d}}$ Public Security Canada, 800 Rue Du Square Victoria, Montréal, Quebec H4Z 1B7 - claude.auger@ canada.ca
}

KEY WORDS: Disaster, Train Derailment, Remediation, NDVI, Optical, SAR, Change Detection

\begin{abstract}
:
On July 6, 2013 a train owned by Montréal, Maine \& Atlantic Railway (MMA) Company derailed in Lac-Mégantic, Quebec, Canada triggering the explosion of the tankers carrying crude oil. Several buildings in the downtown core were destroyed. The Sûreté du Québec confirmed the death of 47 people in the disaster. Through the Canadian Space Agency (CSA) Rapid Information Products and Services (RIPS) program, MDA developed value-added products that allowed stakeholders and all levels of government (municipal, provincial and federal) to get an accurate picture of the disaster. The goal of this RIPS Project was to identify the contribution that remote sensing technology can provide to disasters such as the train derailment and explosion at Lac-Mégantic through response and remediation monitoring. Through monitoring and analysis, the Lac-Mégantic train derailment response and remediation demonstrated how Earth observation data can be used for situational awareness in a disaster and in documenting the remediation process. Both high resolution optical and RADARSAT-2 SAR image products were acquired and analyzed over the disaster remediation period as each had a role in monitoring. High resolution optical imagery provided a very clear picture of the current state of remediation efforts, however it can be difficult to acquire due to cloud cover and weather conditions. The RADARSAT-2 SAR images can be acquired in all weather conditions at any time of day making it ideal for mission critical information gathering. MDA's automated change detection processing enabled rapid delivery of advanced information products.
\end{abstract}

\section{INTRODUCTION}

\subsection{Background}

After the train owned by the company Montréal, Maine \& Atlantic Railway (MMA) derailed on July 6, 2013, it triggered a catastrophic explosion that decimated the Town of LacMégantic, Quebec (Figure 1). Several buildings, homes and the majority of the downtown core of the city was destroyed. On July 11, the Municipality of Lac-Mégantic declared a local state of emergency under Article 42 of the Law on Civil Security. The Sûreté du Québec (Quebec Ministry of Public Security) confirmed the death of 47 people. This disaster was selected as a site to utilize the Rapid Information Products and Services (RIPS) initiative through the Canadian Space Agency (CSA). MDA developed value-added products that allowed stakeholders and all levels of government (municipal, provincial and federal) to get a real picture of the situation on the ground, using map products. This information was shared with all government partners by Public Safety Canada and the Sécurité civile du Québec, including the Town of Lac-Mégantic via a secure portal. The portal also allowed stakeholders to share images in real-time during operations. The images obtained timely results and were broadcast throughout the event and reports provided by federal and provincial Government Operations Centres to all partners across the province of Quebec. The results were also transmitted to Canadian citizens and other interested parties through the website of Open Data Government of Quebec, an ArcGIS Online Portal or through the Quebec Emergency official information releases to the general public.

\subsection{RIPS Program}

The goal of this Rapid Information Products and Services (RIPS) Project, funded through the Canadian Space Agency, is to identify the contribution that remote sensing technology can provide to disasters such as the train derailment and explosion at Lac-Mégantic, Quebec through response and remediation monitoring.

\subsection{Location and Extent of the Disaster}

The Lac-Mégantic train derailment involved 72 tankers each loaded with 113,000 litres of petroleum crude oil. Sixty-three of the 72 tank cars derailed, with many of the tankers rupturing and spilling crude oil. About six million litres of petroleum crude oil was quickly released, with an explosion reported to be over 30 metres high. The fire began almost immediately and burned a land area of over 11 hectares.

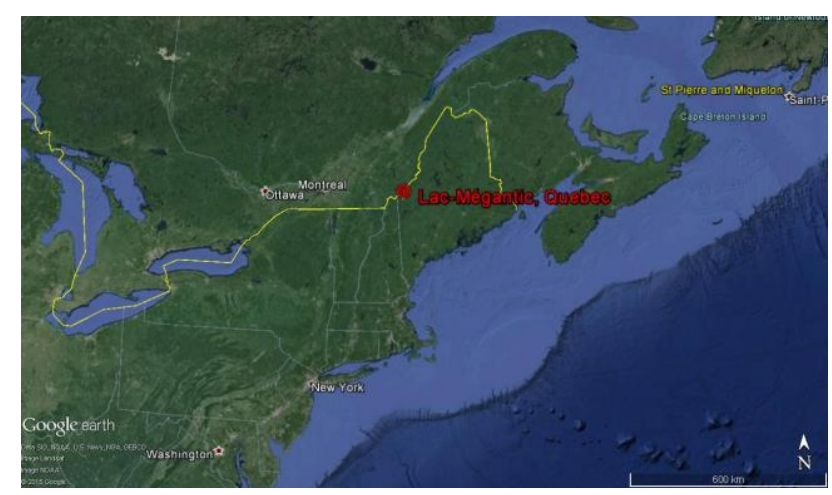

Figure 1. The Location of Lac-Mégantic is approximately $140 \mathrm{~km}$ southeast of Quebec City, Quebec, Canada. 


\section{SATELLITE IMAGES}

\subsection{Image Acquisition Sequence}

Satellite imagery was first acquired through the International Disaster Charter and stored at the USGS EROS Data Center. Frequent optical and RADARSAT-2 Synthetic Aperture Radar (SAR) high-resolution images were acquired approximately every week or two from mid-July through to the end of September as part of the RIPS initiative.

\begin{tabular}{|l|l|l|}
\hline \multicolumn{1}{|c|}{ Satellite Sensor } & \multicolumn{1}{|c|}{ Date } & Resolution \\
\hline WorldView-1 Optical & June 29 juin.2012 & $0.50 \mathrm{~m}$ \\
\hline QuickBird Optical & July 7 juillet, 2013 & $0.61 \mathrm{~m}$ \\
\hline WorldView-2 Optical & July 13 juillet, 2013 & $0.5 \mathrm{~m}$ \\
\hline Pléiades Optical & July 13 juillet, 2013 & $0.5 \mathrm{~m}$ \\
\hline Pléiades Optical & July 29 juillet, 2013 & $0.5 \mathrm{~m}$ \\
\hline RADARSAT-2 Spotlight & July 29 juillet, 2013 & $1.5 \mathrm{~m}$ \\
\hline Pléiades Optical & August 2 août, 2013 & $0.5 \mathrm{~m}$ \\
\hline RADARSAT-2 Spotlight & August 2 août, 2013 & $1.5 \mathrm{~m}$ \\
\hline Pléiades Optical & August 15 août, 2013 & $0.5 \mathrm{~m}$ \\
\hline RADARSAT-2 Spotlight & August 19 août, 2013 & $1.5 \mathrm{~m}$ \\
\hline Pléiades Optical & August 24 août, 2013 & $0.5 \mathrm{~m}$ \\
\hline RADARSAT-2 Spotlight & August 26 août, 2013 & $1.5 \mathrm{~m}$ \\
\hline RADARSAT-2 Spotlight & September 5 septembre, 2013 & $1.5 \mathrm{~m}$ \\
\hline Pléiades Optical & September 6 septembre, 2013 & $0.5 \mathrm{~m}$ \\
\hline RADARSAT-2 Spotlight & September 12 septembre, 2013 & $1.5 \mathrm{~m}$ \\
\hline Pléiades Optical & September 17 septembre, 2013 & $0.5 \mathrm{~m}$ \\
\hline RADARSAT-2 Spotlight & September 19 septembre, 2013 & $1.5 \mathrm{~m}$ \\
\hline RADARSAT-2 Spotlight & September 29 septembre, 2013 & $1.5 \mathrm{~m}$ \\
\hline Pléiades Optical & September 30 septembre, 2013 & $0.5 \mathrm{~m}$ \\
\hline
\end{tabular}

Table 1. Timeline of High-Resolution Satellite Images Acquired The high-resolution $(<1 \mathrm{~m}$ in resolution) optical imagery consisted of 11 image dates as listed in Table 1. The panchromatic band which represents the highest resolution product was used to pan-sharpen the multispectral (MSS) imagery for the display of results at the highest colour resolution possible. The analysis and processing was done on the MSS portion of the data to preserve the integrity of the spectrometry. The footprints of each of these images is shown in Figure 2 below surrounding the "Red Zone" as designated by Public Safety Canada to outline the extents of the disaster.

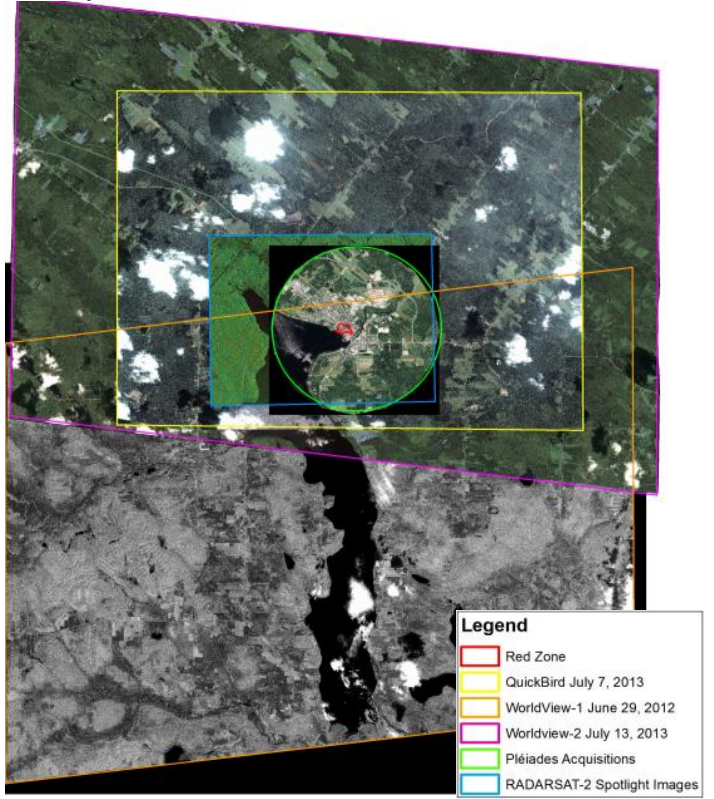

Figure 2. The Footprints of Satellite Images listed in Table 1, acquired for Project use for the Lac-Mégantic Disaster area.
Nine high resolution optical images are displayed chronologically below in Figures 3 through 11.

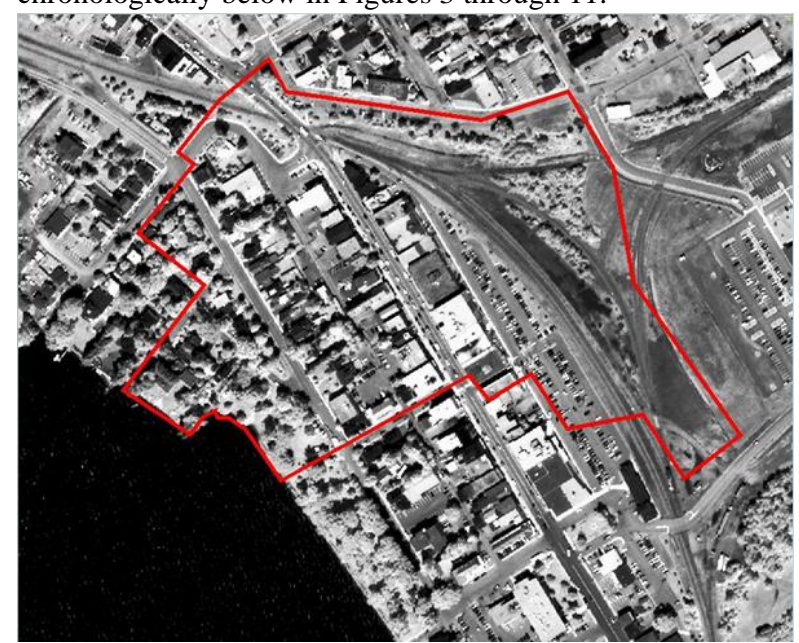

Figure 3. Pre-Derailment Image of Lac-Mégantic,

WorldView-1 image acquired June 29, 2012. (C) DigitalGlobe 2012

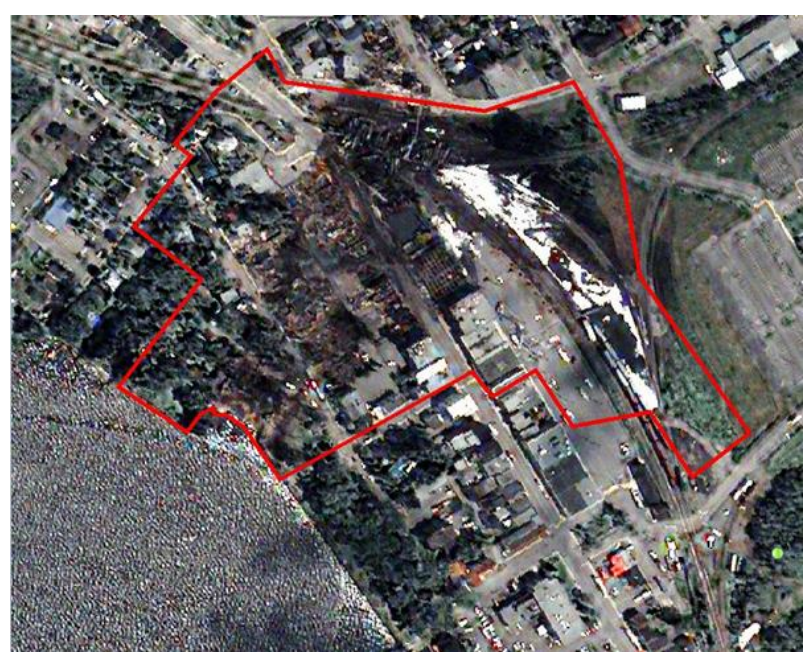

Figure 4. Post-Derailment Image of Lac-Mégantic shows the devastation of the town in the QuickBird image acquired July 7, 2013, one day after the disaster. (C) DigitalGlobe 2013

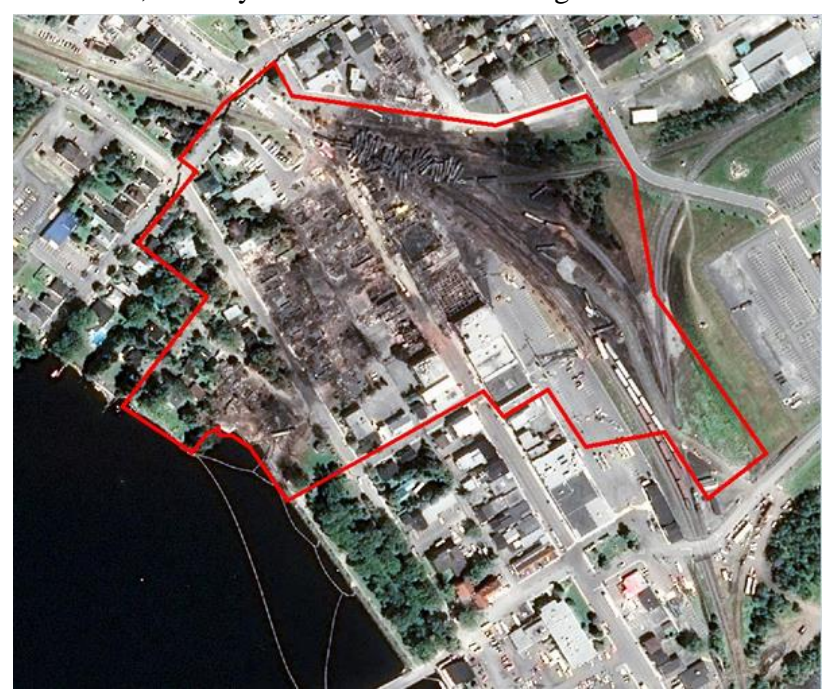

Figure 5. Pléiades image acquired one week post derailment on July 13, 2013. ㄷ CNES 2013, Distribution Airbus DS 
In Figure 5 above, the Pléiades image acquired one week post derailment shows considerable rubble where buildings were located; the train tanker cars remain unmoved though there has been some removal of debris. Booms to contain oil were deployed on the lake, and are visible in the satellite imagery.

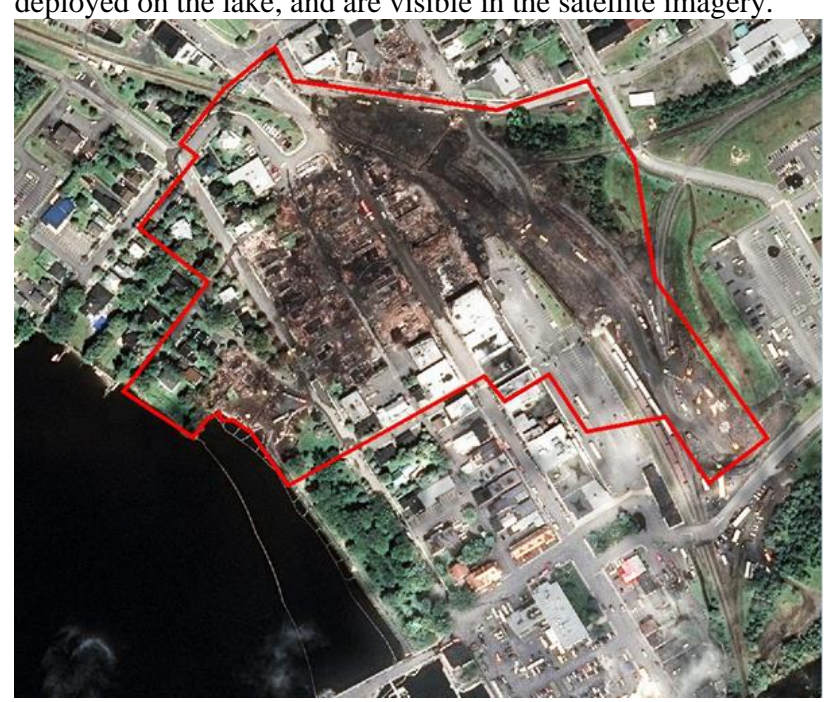

Figure 6. Pléiades image acquired three week post derailment on July 29, 2013. (C) CNES 2013, Distribution Airbus DS

In Figure 6, just over three weeks post derailment, the majority of the train tanker cars have been removed as well as a considerable amount of debris from the fallen buildings from within the red zone. Additional booms can be seen deployed on Lac-Mégantic. In Figure 7, crews continue to remove debris and contaminated soil from the area.

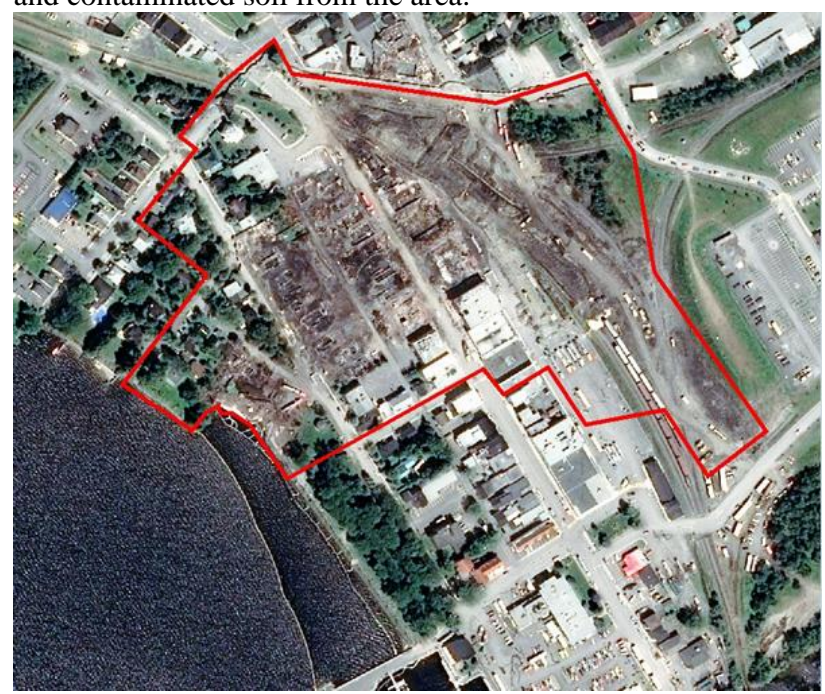

Figure 7. Pléiades image acquired on August 2, 2013. (C) Airbus Defense 2013

Over a month after the derailment and subsequent explosion, Pléiades acquired a cloud-free image on August 15, 2013 as seen in Figure 8. Further excavation of the site continues, and can be monitored easily with the high resolution optical imagery. Most building foundations have now been removed and water has accumulated in one former building location where soil had been excavated. There are fewer vehicles that remain on site.

Images shown in Figures 9 and 10 illustrate the further progress of the reclamation effort by crews on the ground. Most debris and contaminated soil has been removed, the water has evaporated from the building excavation sites.

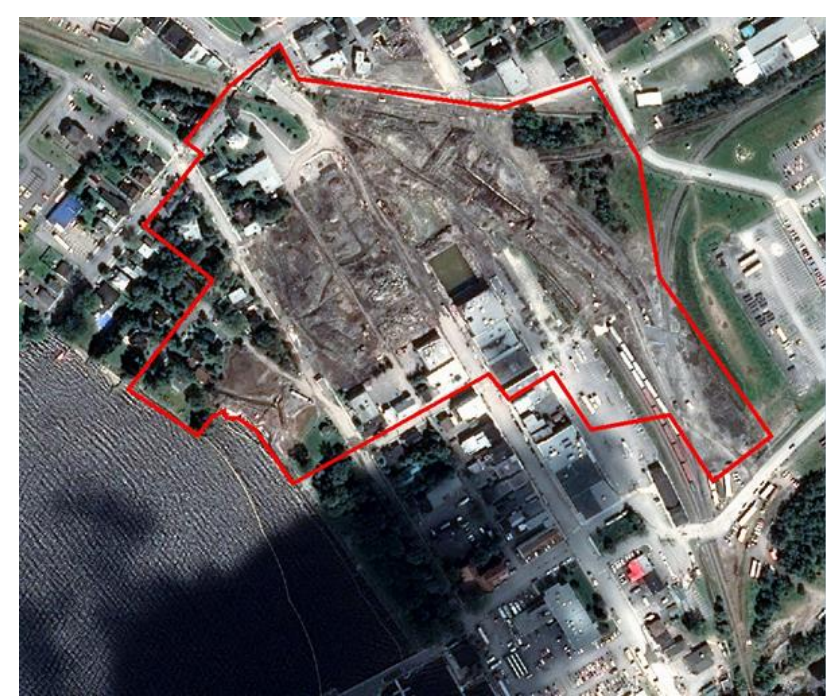

Figure 8. Pléiades image acquired over a month post derailment on August 15, 2013. (C) CNES 2013, Distribution Airbus DS

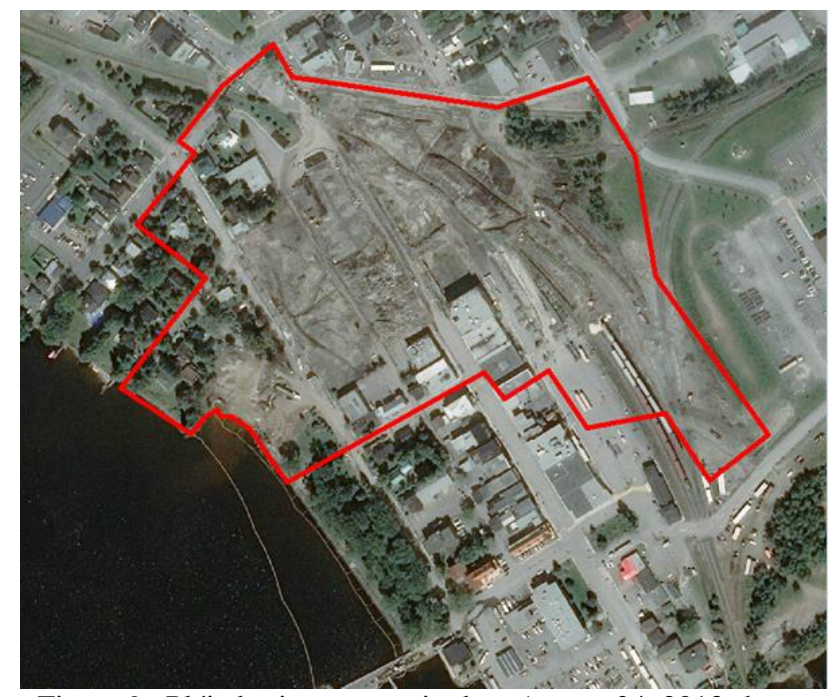

Figure 9. Pléiades image acquired on August 24, 2013 shows the progress of the reclamation effort. (c) CNES 2013, Distribution Airbus DS

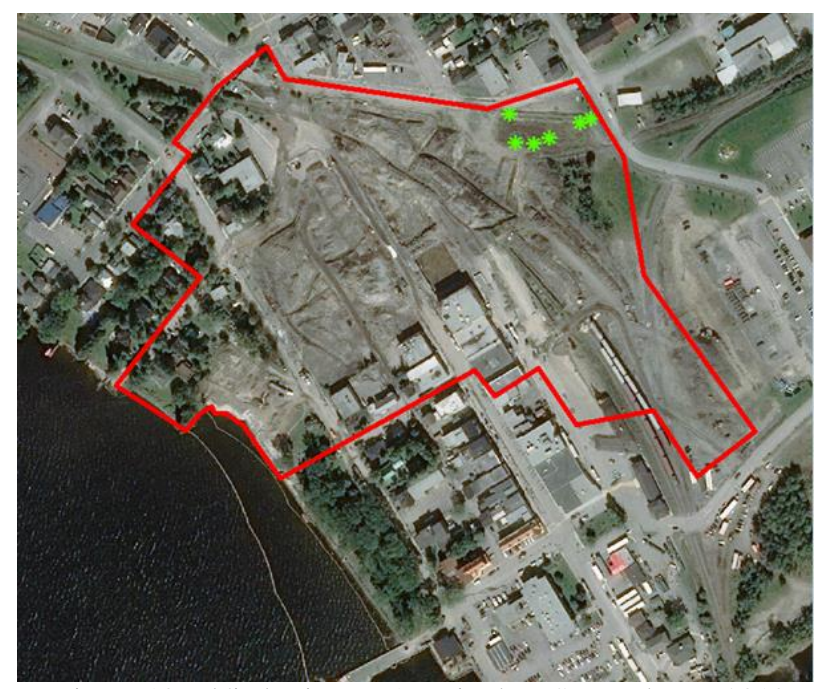

Figure 10. Pléiades image Acquired on September 6, 2013 shows the removal of a stand of trees highlighted in green. (C) CNES 2013, Distribution Airbus DS 


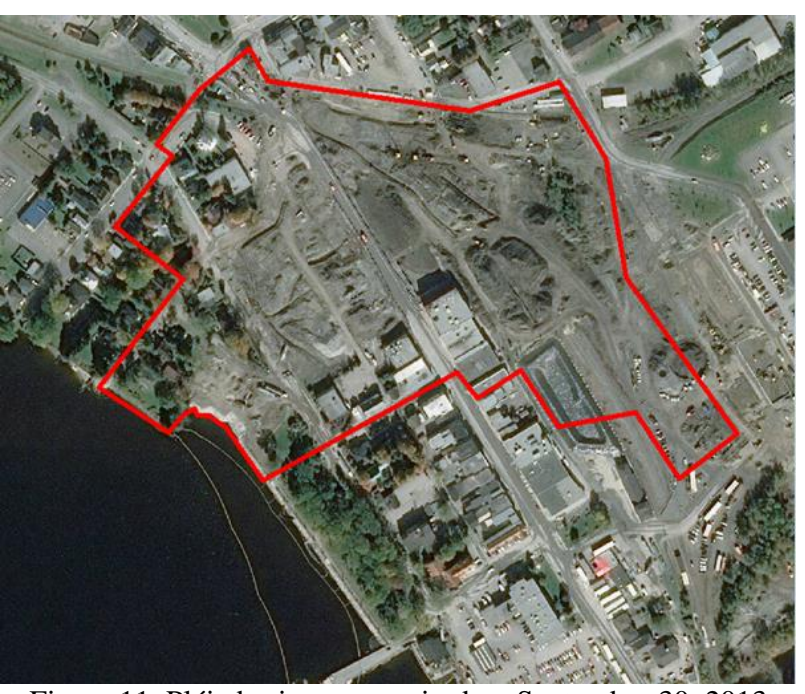

Figure 11. Pléiades image acquired on September 30, 2013 shows evidence of large quantities of fresh soil being stockpiled. (C) CNES 2013, Distribution Airbus DS

\section{CHANGE DETECTION PROCESS}

\subsection{Progressive Change in the Red Zone}

Using the high-resolution optical imagery shown in Figures 3 through 11, new products were generated to create a series of change detection maps illustrating the remediation process as each image was acquired. Features of interest such as the train cars, buildings, and trees were delineated using vectors to depict their removal due to the explosion and/or remediation process. From the before image to after the derailment 28 buildings and 55 trees were demolished, a further stand of between six to ten trees were also removed during the period between the August 26 and September 6, 2013 images. There are 69 distinct train tanker cars visible of the reported 72 present. A subset of these map products are shown in Figures 12 through 14.

$$
\begin{aligned}
& \text { Legend } \\
& \begin{array}{|l}
\square \\
\square \text { Zne rouge / Red Zone } \\
\text { Voie ferrée / Train Tracks } \\
\quad \text { Rue / Roads } \\
\square \text { Hydrologie / Hydrology } \\
\text { Arbres originaux / Trees Original } \\
\text { Arbres démolies / Trees Demolished }
\end{array}
\end{aligned}
$$
$\square$ Bátiments originaux / Bulldings Original

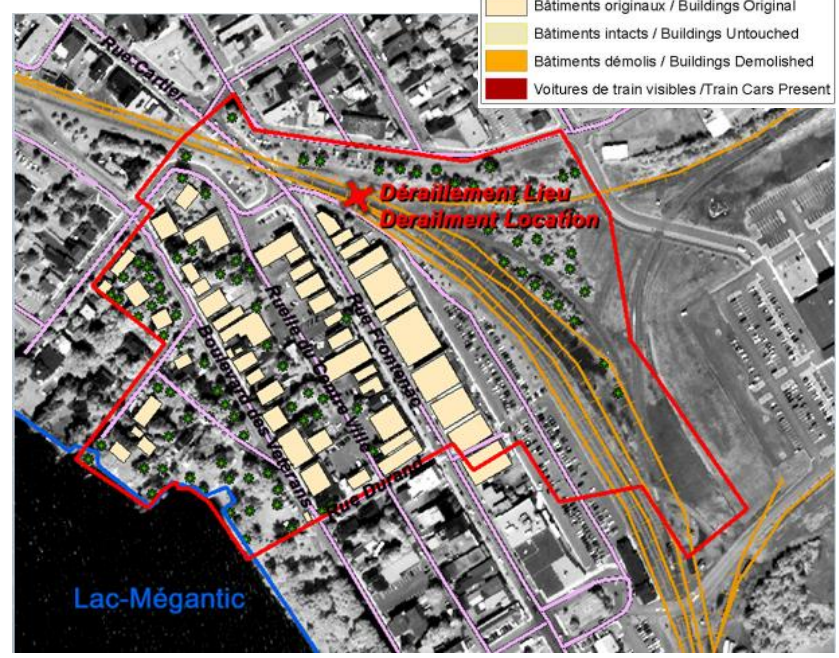

Figure 12. WorldView-1 image acquired on June 29, 2012 illustrates Lac-Mégantic prior to the disaster (C) DigitalGlobe 2012

The Figures 12 and 13 show the state of the town of LacMegantic before and after the disaster. The immediate devastation to the town has been delineated using vectors in

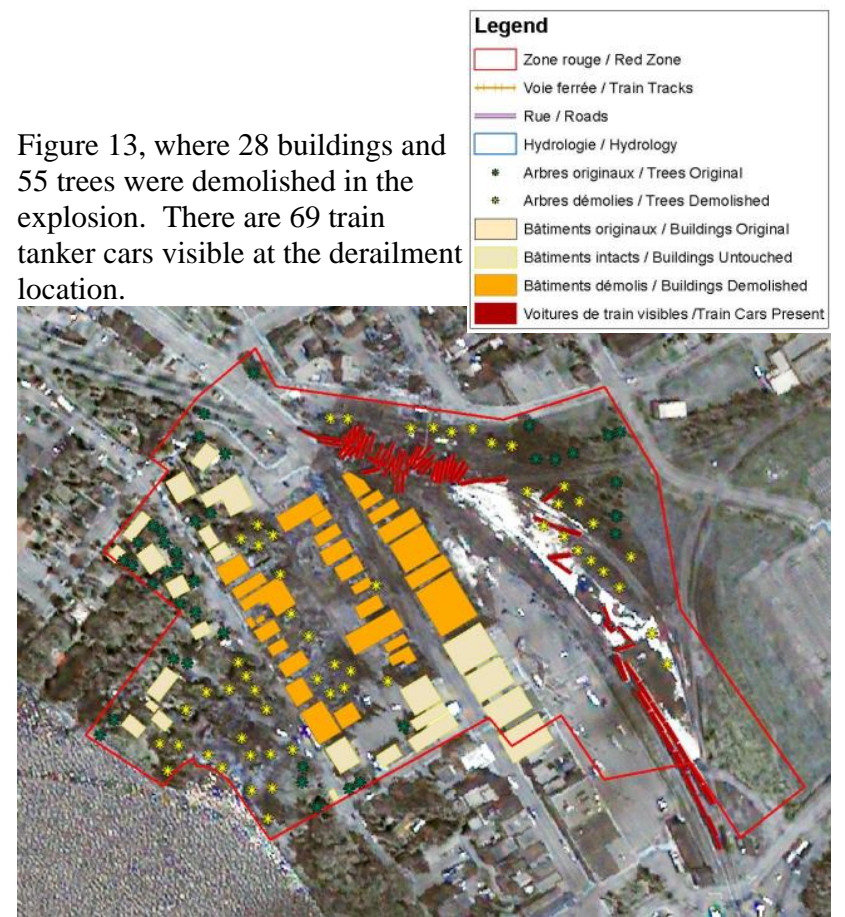

Figure 13. This QuickBird image acquired on July 7, 2013 has been vectorized with the changes to Lac-Mégantic after the disaster. (C) DigitalGlobe 2012

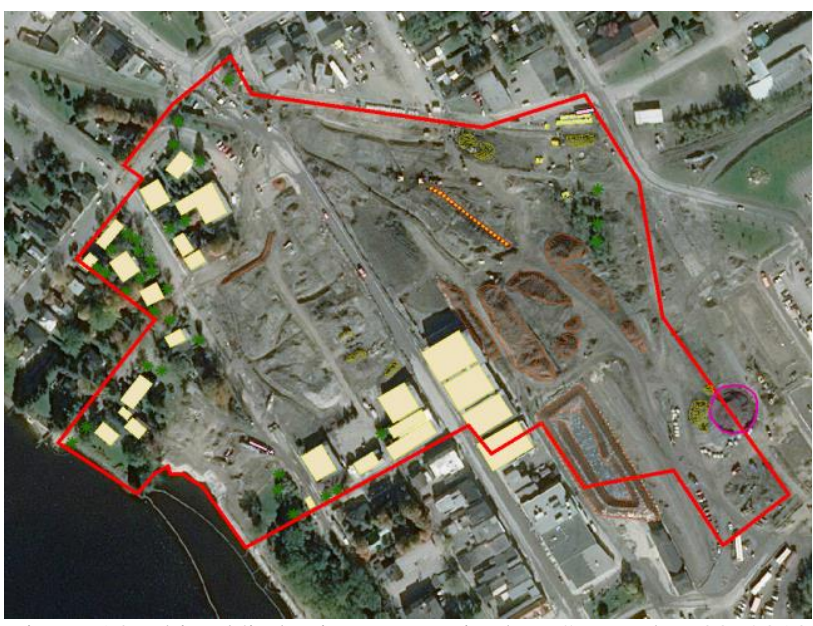

Figure 14. This Pléiades image acquired on September 30, 2013 has additional vectors characterizing the changes three months after the disaster. (C) CNES 2013, Distribution Airbus DS

In Figure 14, berms or soil piles are present as contaminated soil is removed and clean fill is brought in. Excavation continues to the east, with fewer containers on site in the north which were likely the on-site offices of the supervisors and support crew. All train cars have now been removed from the site, even those not involved in the derailment.

The remediation effort was initially hampered by the intense heat and toxic conditions resulting from reported benzene contamination, a component of crude oil. The nearby Veteran's Park on the Lac-Mégantic waterfront and the town's marina that can be seen in the SW corner of the satellite images, were contaminated by the oil, of which containment was attempted via a series of booms. Despite these efforts approximately 100,000 litres of oil entered the Chaudière River and reached as far as $80 \mathrm{~km}$ downstream to further contaminate the local water supply, resulting in a water shortage in 2013. The regular acquisition of Pléiades imagery in the weeks and months after the disaster enabled MDA to monitor and map the changes as the remediation progressed. 


\section{NORMALIZED DIFFERENCE VEGETATION INDEX}

Normalized Difference Vegetation Index (NDVI) is a wellestablished indicator that can be used with satellite imagery to analyze whether a target area contains living green vegetation, and provides a qualitative assessment of the vigor of that vegetation. NDVI is calculated as per Equation 1 below.

$\mathrm{NDVI}=\frac{(\mathrm{NIR}-\mathrm{VIS})}{(\mathrm{NIR}+\mathrm{VIS})}$

Where VIS and NIR stand for the spectral reflectance measurements acquired in the visible (red) and near-infrared regions, respectively. NDVI is based on the fact that healthy biomass will absorb more visible light (VIS) and reflect more in the near-infrared (NIR). In contrast, unhealthy or sparse vegetation will absorb more NIR and reflect more VIS. NDVI ranges from -1 to +1 , where +1 implies the highest green-leaf biomass density and hence the most healthy.

The NDVI results were grouped into 10 classes and are illustrated in Figure 15. Blue or red colours show very low values typically associated with water or bare earth. Orange and yellow were either transitional or indicative of stress or considered to be a low value typically characterized by soil and low density of any biomass. Anything that is green was considered vegetation. An increasing deep colour of green represents an increased amount of biomass.

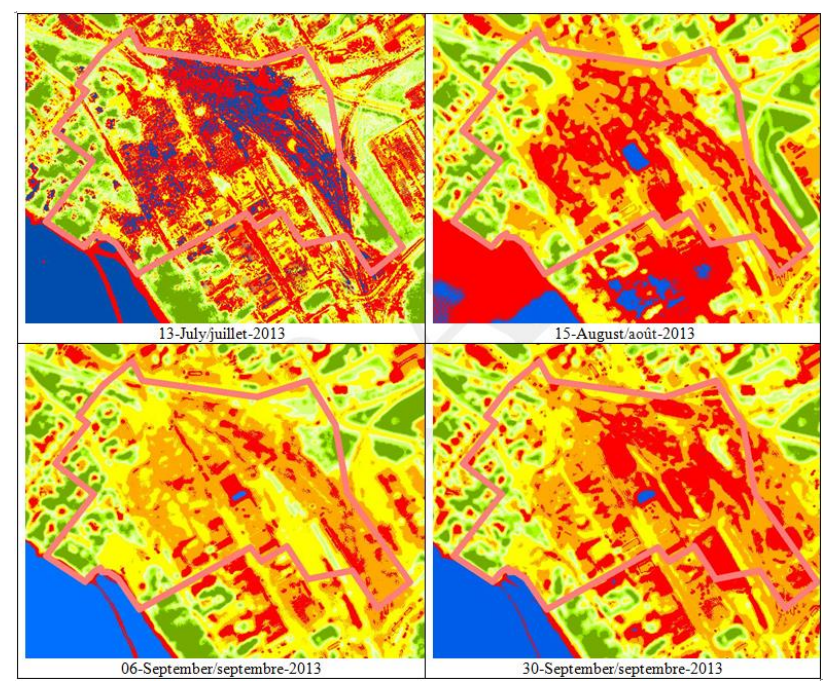

Figure 15. Time progressive NDVI results for the Lac-Mégantic Red Zone. () MDA, All Rights Reserved.

The changing NDVI results visible in the remaining vegetation for the progressive dates after the explosion is due primarily to the removal of soil, and the changing of seasons. Yearly monitoring will determine whether the hydrocarbons that leached into the ground will significantly impact the health of the remaining trees and parks over the next decade.

\section{RADARSAT-2 CHANGE DETECTION ANALYSIS}

RADARSAT-2 Spotlight data was acquired in HH polarization, with the dates outlined in Table 1 . The Spotlight change detection analysis is visualized using a simple red-blue change detection algorithm. The algorithm consists of generating a composite image (RGB) where the red band contains the earlier date and the green and blue bands contain the latter date. In the composite image, pixels with redder tints indicate that backscatter was higher in the earlier date, whereas pixels with bluer tints indicate that backscatter was higher in the latter date. White and black pixels indicate high or low backscatter on both dates. The mnemonic for interpretation is described by the phrase "blue is new" (increase in backscatter or recent construction), "red has fled" (decrease in backscatter or recent demolition). Such composites can be formed for each sequential date-pair (i.e. date 1 to date2, date 2 to date3, etc.). There were nine image sequential change detection processes run for the duration of this project, however only three image date pairs were showcased in this paper for brevity.

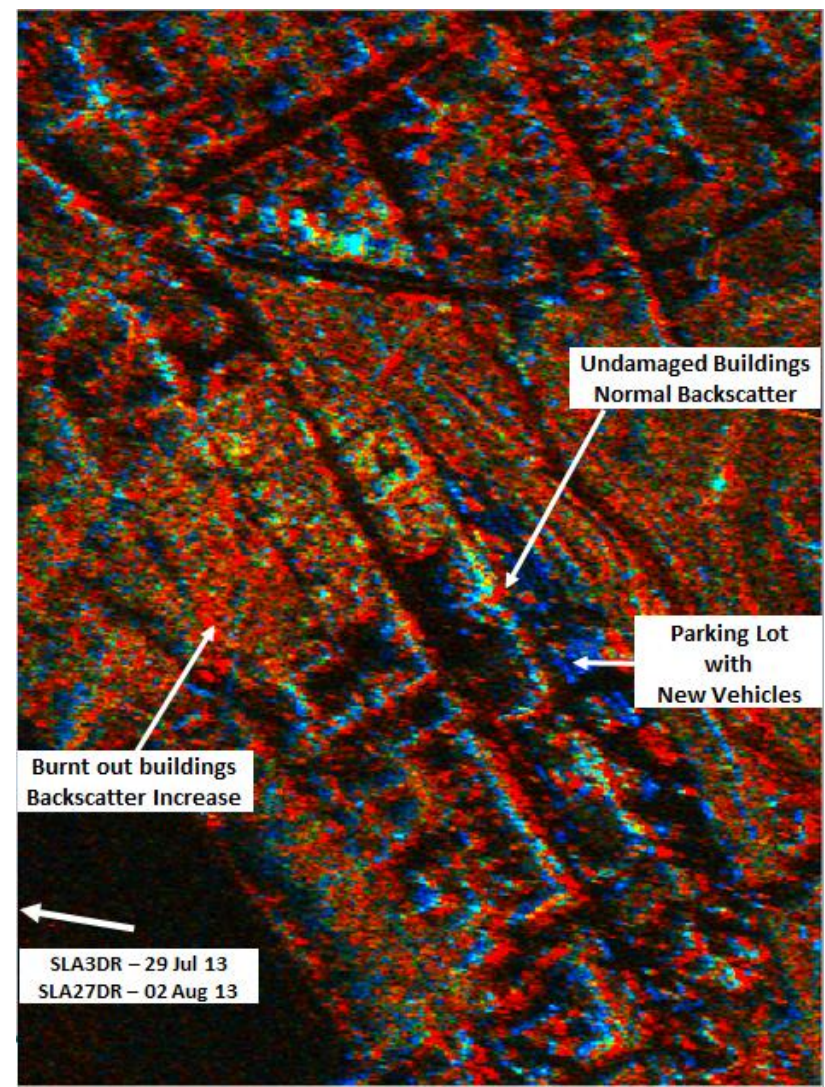

Figure 16. Comparing change between image dates of 29 July, 2013 and 2 August, 2013.

RADARSAT-2 Data and Products $\odot$ MacDonald, Dettwiler and Associates Ltd. 2013. All Rights Reserved. RADARSAT is an official mark of the Canadian Space Agency.

Comparing the intact buildings in the commercial district in the lower center portion SAR image in Figure 16 with the buildings that were destroyed by the fire, the clean specular surface characteristic of buildings is no longer present, and the returns from those areas on the SAR imagery are quite noisy from the debris on the ground. The parking area shows an increase of vehicles between the two SAR images.

In Figure 17, the red returns from the areas of destroyed buildings signifies that the damaged material is being removed. Significant changes are seen in the amount of building debris, it appears that the vehicles or equipment have been removed from the parking lot. There is a new blue return that is sitting in the middle of the north end of Rue Frontenac with a long winding return running down the middle of the street into the destroyed portion of the town. It is assessed as a probable vacuum truck with a tanker unit and the blue line would represent a hose set up. They are probably removing oil and water that has collected in the building foundations and the streets/yards. 


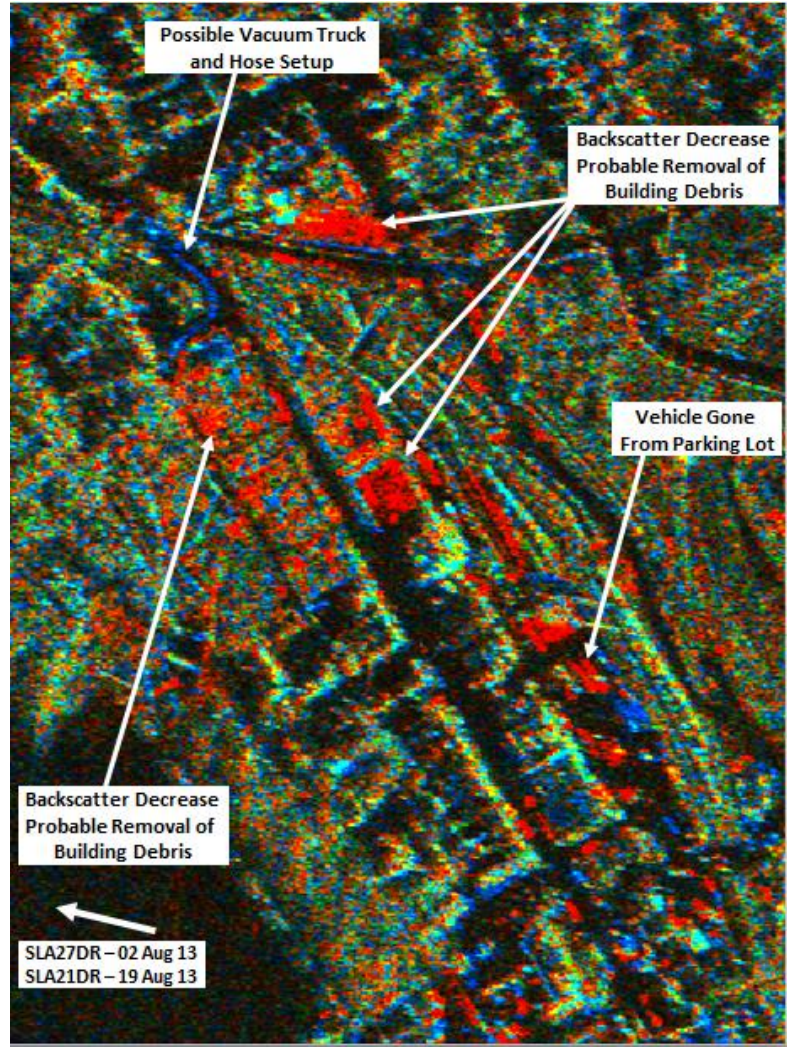

Figure 17. Comparing change between image dates of 2 August, 2013 and 19 August, 2013.

RADARSAT-2 Data and Products @ MacDonald, Dettwiler and Associates Ltd. 2013. All Rights Reserved. RADARSAT is an official mark of the Canadian Space Agency.

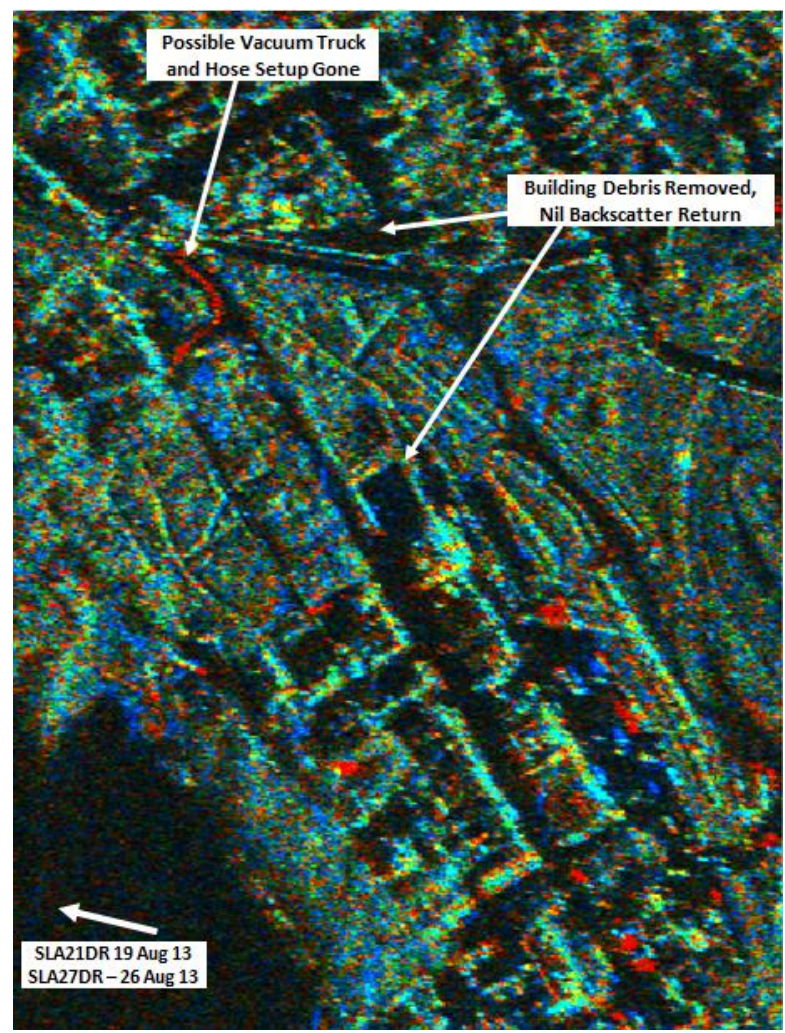

Figure 18. Comparing change between image dates of 19 September, 2013 and 29 September, 2013.

RADARSAT-2 Data and Products $\odot$ MacDonald, Dettwiler and Associates Ltd. 2013. All Rights Reserved. RADARSAT is an official mark of the Canadian Space Agency.
The first change evident in Figure 18 is that the vacuum truck and hose set up has been removed. The three areas of red from the previous SAR comparison have come back as very specular indicating that all the material has been removed, and there is likely only smooth concrete remaining. The parking area east of the commercial district continues to see vehicles coming and going. The bulk of the destroyed area on the southwest side of the road continues to show work being done to remove material.

\section{CONCLUSION}

The monitoring analysis of the Lac-Mégantic train derailment response and remediation demonstrated how Earth observation data can be used for situational awareness in a disaster and remediation process. Both high resolution optical and SAR image products were acquired and analyzed throughout the disaster and following remediation period. The SAR imagery highlighted changes to the surface roughness as the site was being cleared of debris and contaminated soil. It was also useful in monitoring the movement of vehicles and clean-up infrastructure. The high resolution optical imagery provided excellent clarity on the emergency response activities including the derailed train tankers, destroyed buildings and vegetation.

Both optical and SAR imagery have a role in monitoring the remediation process after any disaster. High resolution optical imagery provides a very clear picture of the current state of remediation efforts, however it may be difficult to acquire due to cloud cover and weather conditions. The SAR images can be acquired in less than ideal weather conditions (e.g. clouds) and at any time of day, and automated change detection analysis can highlight differences between image dates. The resulting change products can be more difficult to interpret without a trained image analyst providing the context of that change. Figure 19 shows the optical and SAR datasets fused together in order to maximize interpretability of viewing the SAR and Pléiades datasets.

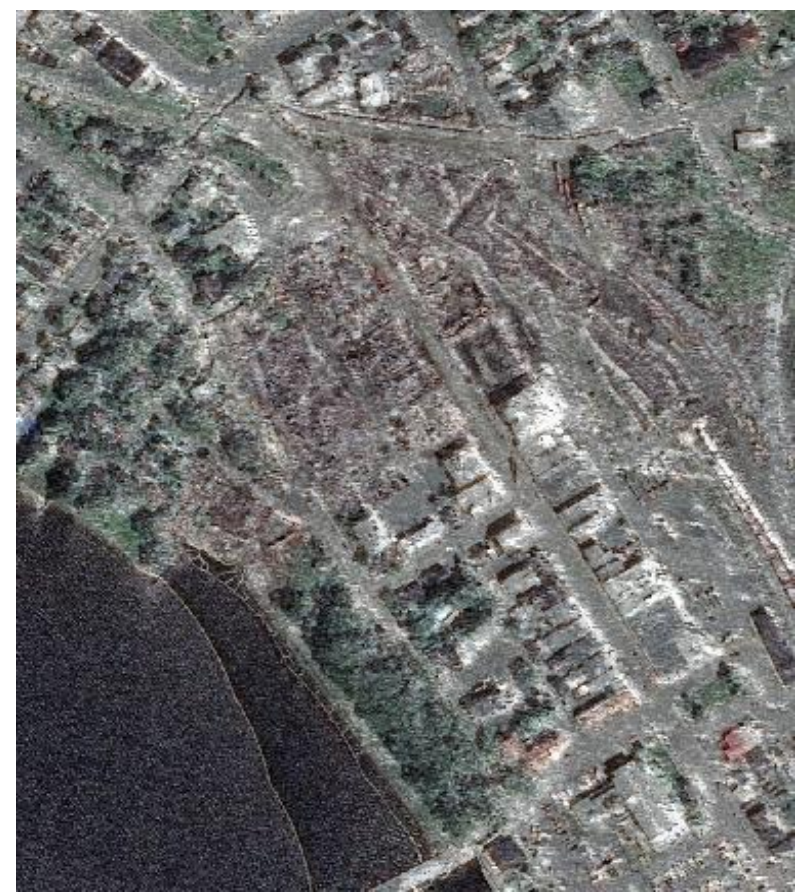

Figure 19. Both Pléiades and RADARSAT-2 were acquired on August 2, 2013 to generate this Fused RGB Composite. RADARSAT-2 Data and Products $\odot$ MacDonald, Dettwiler and Associates Ltd. 2013. All Rights Reserved. RADARSAT is an official mark of the Canadian Space Agency. Pléiades data @ CNES 2013, Distribution Airbus DS. 
Figure 19 was generated by fusing the multispectral bands of the colour Pléiades image and the intensity of RADARSAT-2 Spotlight image, both acquired on August 2, 2013. The resulting image shows the colour from the optical scene coupled with the texture and finite details from the SAR and can aid in SAR interpretation.

\subsection{Future work}

The Quebec Ministry of Public Security acquired two additional high resolution optical satellite images outside of the purview of this project. These images enabled the stakeholders to continue monitoring the on-going remediation efforts years later.

Due to the extent of the disaster and the chemicals involved, the cleanup of the derailment and explosion area could take up to five years or more. Approximately 115 businesses may need to relocate, in addition to the 40 buildings that were destroyed in the blast. Further upwards of 160 may need to be expropriated for demolition as they are located on several metres of contaminated soil.

The following Figures 20 and 21 further demonstrate the use of high resolution satellite imagery to maintain yearly monitoring on the progress of the site remediation. Figure 21 shows the additional buildings that have been removed due to wide-spread contamination of hydrocarbons below the building framework.

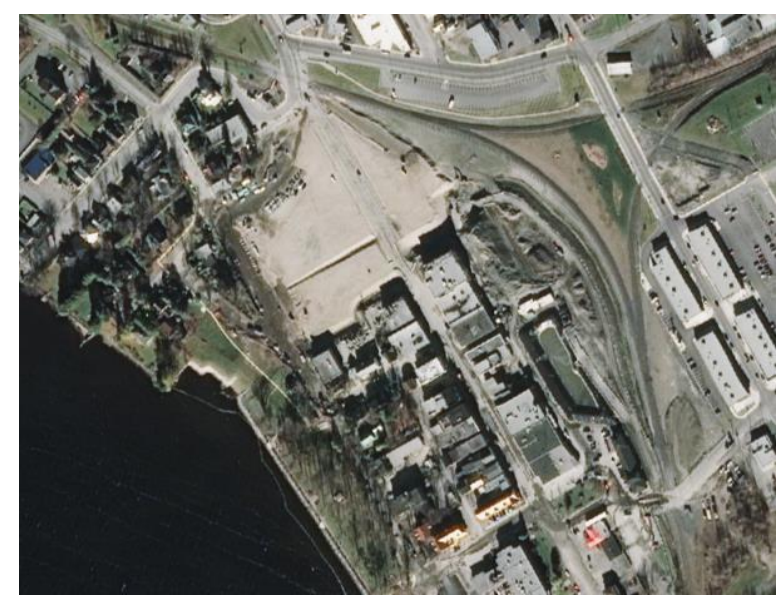

Figure 20. This Pléiades image Acquired on November 3, 2014 illustrates the progress of the remediation 16 months postderailment. (C) CNES 2014, Distribution Airbus DS

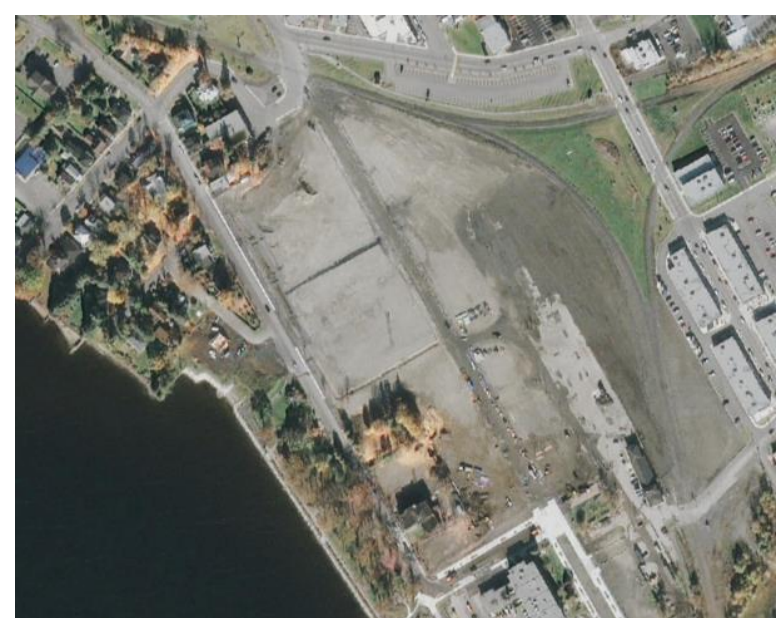

Figure 21. This Pléiades image from October 19, 2015 is the most recent optical image of the disaster site, note the number of newly removed buildings.

(c) CNES 2015, Distribution Airbus DS

\subsection{Summary}

The high-resolution optical imagery and the high-resolution RADARSAT-2 imagery were the focus and the tools of this project as the main objective was to determine a clear picture of what remote sensing or Earth observation technologies can bring to the table for occasions of disaster response.

Taking the derived image and vector change products and summary report deliverables, both the Quebec Ministry of Public Security and Public Safety Canada integrated these products into their operational GIS Systems. It was useful to corroborate the input coming from the ground operations, with the Project deliverables, as it gave a broader picture of the remediation efforts. Both Government Agencies had some valuable lessons learned, one of which was that they needed to increase internal user capacity to fully exploit the information coming from all sources; which could include a future Federal Geospatial Platform.

It was found that the changes from the derailment, explosion and remediation efforts were clearly evident in both image sources, with the caveat that the user has the software and the expertise to process and extract information from those changes. The deliverables included processed imagery, ESRI shapefiles of the changes delineated in vector form and a summary report.

The second part of the project looked at the vegetation health analysis using NDVI. In this study the majority of vegetation that was not destroyed in the explosion was subsequently removed due to contamination, leaving very little vegetation present, so the NDVI calculations had limited value.

In conclusion, there were benefits to using both high resolution optical imagery and also high resolution SAR imagery for emergency and disaster response. The benefits that each methodology brought were quite different, thus suggesting that the most successful project should have access to both sensors. It was found that the optical imagery presented a clear picture of the current state of remediation efforts, while the SAR imagery highlighted minute changes to the surface roughness that were not visible in the optical imagery.

\section{ACKNOWLEDGEMENTS}

The authors would like to acknowledge the support of the Canadian Space Agency for the RIPS Funding. The authors also like to thank the Quebec Ministry of Public Security and also Public Safety Canada for providing their expertise.

\section{REFERENCES}

Lac-Mégantic runaway train and derailment investigation summary. Transportation Safety Board of Canada's (TSB) Railway Investigation Report R13D0054. October 2014.

Aubé, G., Werle, D., Seguin, G., Saulnier, J., Frye, S., Alleyne, N., Arsenault, E. Gaetani, F. 2013. Radarsat-2 Contributions To The Caribbean Satellite Disaster Pilot During Hurricane Seasons 2010, 2011 and 2012. Living Planet Symposium 9-13 September, 2013. Edinburgh, Scotland.

Luscombe, A., 2001. RADARSAT-2 Product Specification, Richmond, Canada: MacDonald Dettwiler RN-SP-50-9786

Secker, J., Vachon, P. 2007. Exploitation of multi-temporal SAR and EO satellite imagery for geospatial intelligence. In Proceedings of Fusion 2007: The $10^{\text {th }}$ International Conference on Information Fusion, 9-12 July 2007, Quebec City, Canada. pp. 8 